\title{
Establishing a Framework of Influential Factors on Empowering Primary School Students in Peer Mediation
}

\author{
Hamideh Jorbozeh ${ }^{1}$; Tahereh Dehdari ${ }^{1}$; Mahnaz Ashoorkhani ${ }^{1}$; Mohammad Hossein \\ Taghdisi ${ }^{1, *}$ \\ ${ }^{1}$ Department of Health Promotion and Education, Tehran University of Medical Sciences, Tehran, IR Iran \\ ${ }^{*}$ Corresponding Author: Mohammad Hossein Taghdisi, Department of Health Promotion and Education, Tehran University of Medical Sciences, Tehran, IR Iran. Tel/Fax: +98- \\ 2188779118, E-mail: m-taghdisi@tums.ac.ir
}

Received: August 15, 2013; Revised: January 7, 2014; Accepted: March 8, 2014

\begin{abstract}
Background: Empowerment of children and adolescents in terms of social skills is critical for promoting their social health.
Objectives: This study attempts to explore a framework of influential factors on empowering primary school students by means of peer mediation from the stakeholders' point of view, as a qualitative content analysis design.

Patients and Methods: This study was a qualitative content analysis (conventional method). Seven focused group discussions and six in-depth interviews were conducted with schoolchildren, parents and education authorities. Following each interview, recordings were entered to an open code software and analyzed. Data collection was continued up to data saturation.

Results: Within the provided framework, the participants' views and comments were classified into two major categories "educational empowerment" and "social empowerment", and into two themes; "program" and "advocacy". The "program" theme included factors such as design and implementation, development, maintenance and improvement, and individual and social impact. The "advocacy" theme included factors such as social, emotional and physical support.

Conclusions: The explained framework components regarding peer mediation are useful to design peace education programs and to empower school-age children in peer mediation.
\end{abstract}

Keywords:Primary Schools; Empowerment; School Health; Mediation; Education

\section{Background}

Pinocchio was a wooden puppet who dreamt of becoming a real boy. The Blue Fairy told him that if he proved himself to be truthful, unselfish and brave, he would become a real boy; and so, his adventures began. However, the Blue Fairy's guidance was not the mere factor that helped Pinocchio to become a real boy. Getting involved in confrontations and problems in the natural process of life helped him to turn into a real boy. Creating unique confrontational opportunities for children to face real life problems as well as creating a suitable environment is necessary for empowering their social skills (1). Since children come to school with different backgrounds, values, experiences and viewpoints, conflicts are an integral part of school life. They play an important role in children's moral cognition and psychosocial development (2). Conflicts may seem inefficient at first, but in the long run they may prove to be effective, and if resolved through nonviolent ways, they lead to empowerment of the society $(3,4)$. Peace education and peer mediation program use a proactive approach to teach children how to peacefully communicate with others and provide them with creative methods in case of a conflict $(5,6)$. By creating behavioral norms and educative conflict resolu- tions, peace education gives children special experiences, which in return increases their abilities (7). Peer mediation, as an important part of many peace education programs, is a restorative method of conflict resolution, in which a neutral third party helps disputants solve their problems to achieve a mutual agreement (8). Teaching schoolchildren the structural management of their conflicts to resolve the confrontations they have with their peers will help them to be empowered and balance their behaviors (6). Schools positively affect children and youth's health by teaching them a wide variety of skills $(9,10)$. Schools provide a communicative atmosphere for schoolchildren, teachers, and staff. By creating the necessary support, they can lead to permanent empowerment of schoolchildren and their families $(11,12)$. Most schoolage children are ill-equipped with resolving conflicts (13) and the lack of interpersonal conflict management usually leads to violence (14).

\section{Objectives}

Considering the necessity of peace education programs on this issue as well as the lack of a native framework to indicate effective factors on empowering schoolchildren

Copyright ( ) 2014, Iranian Red Crescent Medical Journal; Published by Kowsar. This is an open-access article distributed under the terms of the Creative Commons Attribution-NonCommercial 4.0 International License (http://creativecommons.org/licenses/by-nc/4.0/) which permits copy and redistribute the material just in noncommercial usages, provided the original work is properly cited. 
Jorbozeh Het al.

\begin{tabular}{|c|c|c|c|c|c|c|c|c|c|}
\hline \multirow[t]{2}{*}{ Participants } & \multirow[t]{2}{*}{ Number } & \multirow{2}{*}{$\begin{array}{c}\text { Average } \\
\text { Age }\end{array}$} & \multicolumn{2}{|c|}{ Gender } & \multicolumn{3}{|c|}{ Education } & \multicolumn{2}{|c|}{ Occupation } \\
\hline & & & Female & Male & Diploma & Bachelor & Master & Employee & Housewife \\
\hline Parents & 11 & 45.2 & 7 & 4 & 2 & 7 & 2 & 6 & 5 \\
\hline $\begin{array}{l}\text { Education authorities } \\
\text { and Experts }\end{array}$ & 10 & 46.7 & 4 & 6 & 1 & 8 & 1 & - & - \\
\hline Students & 24 & 10.6 & - & 24 & 4 th and 5 th grade & & & - & - \\
\hline
\end{tabular}

in peer mediation, this study planned to explain the experts and stakeholders' opinions to establish a framework of influential factors on empowering primary school students in peer mediation.

\section{Materials and Methods}

\subsection{Context}

A qualitative content analysis (conventional method) was designed to find a framework of influential factors on empowering primary school students in peer mediation. Participants were selected from a school in the sixth district of Tehran, where the schoolchildren's empowerment interventions for conflict resolution had been conducted (15) by the researchers of the present study. The study was conducted from March to July 2012. Participants who met certain criteria were selected through purposeful sampling (maximum variation method). The selection criteria were: the person's agreement to participate, all of whom were from the school where the educational intervention on the schoolchildren's peace education and empowerment had been conducted (16). Totally, 26 semi-structured interviews were conducted with fourth and fifth grade male students $(n=24)$, their parents $(n=10)$, and education authorities $(n=11)$. Demographic characteristics of these participants are presented in Table 1.

Before each interview, the research goals were explained to the participants, who knowingly gave their consent to the audio recording of the interviews. They were given full authority to either accept or refuse participation. Furthermore, the research proposal was approved by the Ethics Committee of Tehran University of Medical Sciences (Grant No. 90-04-62-16277).

Data collection was performed through focus group discussion and in-depth semi-structured interviews with the participants $(17,18)$. The sessions were carried out using a semi-structured interview guide, were consistent with the study objectives, and were also appropriate for each group of participants. The guide validity was evaluated and corrected throughout the first sessions. A researcher, with nine years of experience in teaching life skills to schoolchildren, being a family education expert at primary schools, conducted the interviews. Discussions and in-depth interviews lasted 45 to 70 minutes and began with some general questions in regard to group of participants (i.e. what is your opinion about peer mediation program?, what are the impacts of this program on your school?, what pleasant and unpleasant experiences did you have during the implementation of the program?, what are the main factors that help the program improve?). Different probes were launched according to the participants' answers for stirring up discussions on the subject affair. Participants, especially students, were persuaded to talk freely and to share their feelings and experiences with other members of the group. None of the participants withdrew or got excluded from the study.

\subsection{Data Analysis}

This qualitative study was conducted using thematic analysis. The interviews (data collection) continued until data saturation, when no new information came to light. The audio files were transcribed verbatim for the purpose of this study using the Open Codes software (3.4). At first, the transcript was reread separately by two individuals to achieve an overall impression. Then, researchers identified meaning-units from the transcripts and fulfilled initial coding, based on the participants' phrases. These codes were classified again based on their similarities and differences for identifying themes (19). Codes and themes were read several times by other member of the research group to identify major themes and categories. To examine the reliability and level of agreement between the two, 150 lines from each of the in-depth and group interviews were selected. Each of the topic codes and categories were compared. The level of achieved agreement was $92 \%$. Themes and subthemes were finalized in a research team meeting and reviewed by two professors of Tehran University of Medical Sciences to ensure that the data analysis was verifiable as suggested by the experts. The evaluation criteria for making the trustworthiness of qualitative data were also checked $(20,21)$. The participants' views and comments fell into two main categories.

\section{Results}

The results of the participants' comments about the influential factors on empowering students in peer mediation were classified into two main groups: educational and social empowerments. They were categorized into two themes: program and advocacy (Figure 1). The "program" theme was classified into four subthemes: design and implementation, development, maintenance and improvement, and individual and social impact. The "advocacy" theme was divided into three subthemes: social, 
emotional, and physical support. The interviewees were allocated a special code depending on who they were and these codes were used at the end of their quotes: schoolchildren were represented as S 1-24; parents as P 1-10, and education authorities and staff as E.A.1-11.

\subsection{The Advocacy Theme}

All the participants pointed out the effective role that "advocacy" played as an influential factor in peace education and empowerment of schoolchildren's peer mediation.

\subsubsection{Social Support}

Most interviewees mentioned the support given by the family, school, society (children's playground), and the cooperation between the school and family. "The teachers, schoolmaster and principal counted on us. They first sent the kids, who went to them to complain, to us, and later dealt with the matter themselves" (S 3).

"Encouraging and actualizing the project outside the school, in society, and at home is very important. For example, his father and I had a disagreement. He said "I can help!" and gave each of us a glass of water, told us to count to ten and start over. We gave him a chance to express himself" (P 7).

"Introducing this project in the beginning was quite effective and helped the parents a lot. When we told the parents that we planned to do this and got their cooperation, it was very effective" (E.A. 5).

\subsubsection{Emotional Support}

Many of the interviewees commented on the need for emotional support from the family, immediate family, school, and peers. "There was a third-grade student who would come to the peace station, and when he saw my friend and I, he would say "hey, how are you doing?" That was really cool! (S 12).

"The best way parents can support their children is to encourage them. They can participate in home in different ways, to follow up the educator's path at home. This will benefit both their children and the society" (P 2).

"When the mediators come to my office and have a question or have something to do, I support them and have a meeting with them" (E.A.10).

\subsubsection{Physical Support}

Most of the stakeholders in this study pointed out the significance of school atmosphere, mediators' clothes and hats, peace treaties and stations, and their effective roles in implementation of the program. "We really liked it when we sat at the peace station. Other kids saw us and it drew their attentions" (S15).

"The playground is now filled with peace and if children have problems they will go to the peace stations" (E.A. 1).

"The fact that they stay at the stations as a group helps their communication as well as their socialization" (E.A. 6).

\subsection{Program Theme}

Based on their perspectives, participants made different comments on the program. These views included the program's design and implementation, development, maintenance and improvement, and finally impact (on individual and social empowerment).

\subsubsection{Design and Implementation}

Many participants believed that factors that influenced the program execution were educational method, peace educator's behavioral characteristics, classroom teachings, experiential learning in school grounds, and the way mediators were selected. Some of the statements made are as follows:

"If they do not take turns, they will lose their right to be chosen. For example, I myself have a right to be chosen even if I were to be a naughty boy before, but now as I am a good boy, my right must not be denied" (S 20).

"They could not have done anything worthwhile if it was only in theory. The practical sessions have honestly been quite effective" (P 11).

\subsubsection{Development}

A large number of interviewees suggested the following: educating students in lower grades, expanding and developing the program for other educational levels (middle school), educating parents and teachers and finally those in higher grades. "Not all mothers have the right knowledge. Upbringing varies in different families. A lot of children have problems at home. Education affects this. As they have no knowledge (mothers), they should be educated" (P 6).

"Experts who have had experience in this field of work should come (to school) so that the classes, workshops and teaching sessions can be held" (E.A. 9).

\subsubsection{Maintenance and Improvement}

From the interviewees' point of view, the following factors resulted in the maintenance and improvement of the program: the support and participation of education authorities and parents, the program's feedback on parents, coordination between education authorities and parents, encouraging and supporting the schoolchildren. "The first- and second-graders come and ask us questions because of the competitions you hold. This makes us happy" (S 19).

"We must provide parents with the sufficient education and information. Very few appreciate the school's website. The same old method of giving away brochures is much better. This way they will even participate more often" (P 4).

\subsubsection{Impacts}

The majority of the participants believed the program impacts, as individual and social empowerments are 


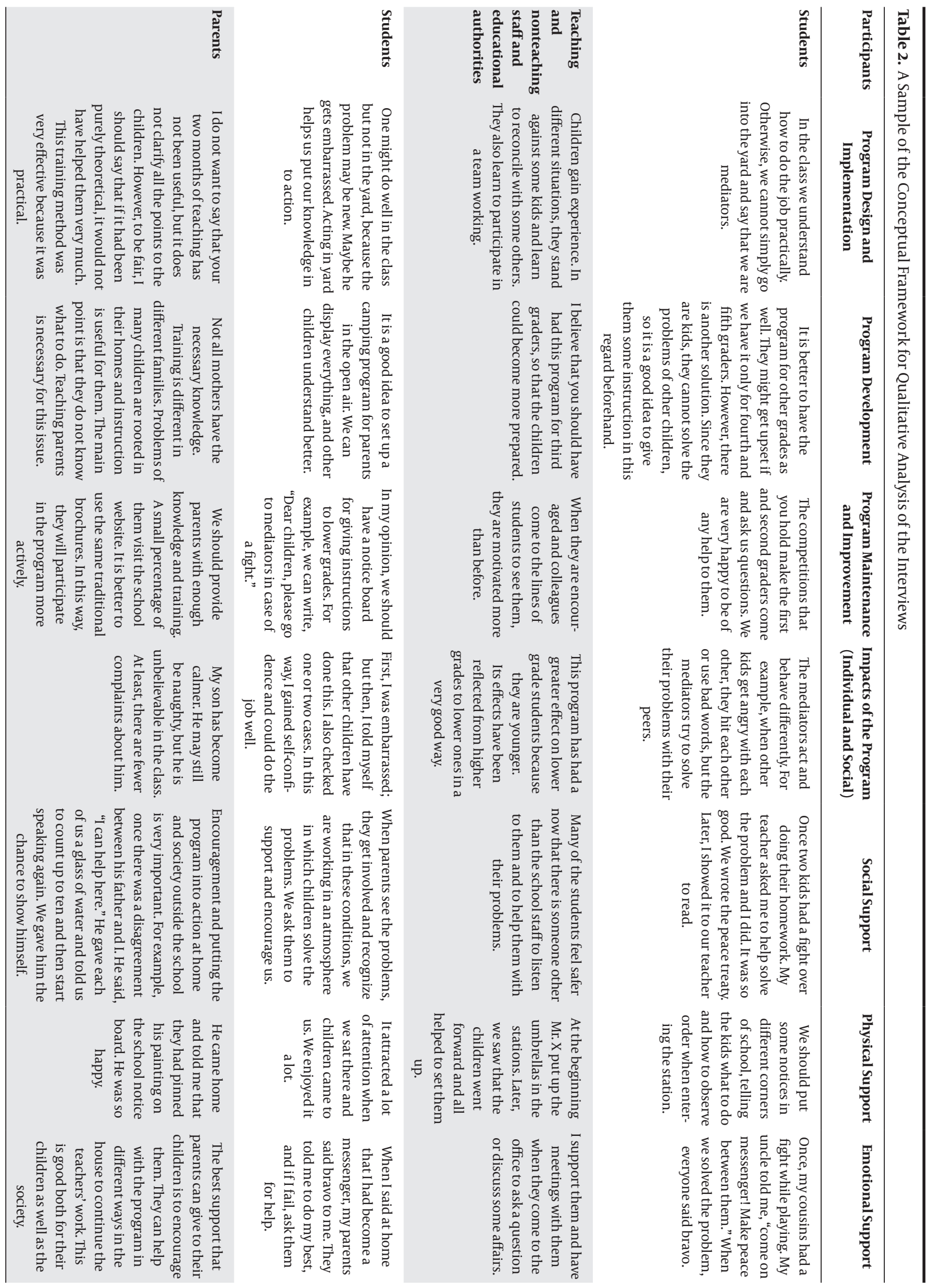


Table 3. Themes, Subthemes, and Extracted Codes From the Interviews

\begin{tabular}{|c|}
\hline Social Empowerment \\
\hline Advocacy \\
\hline Social support \\
\hline School \\
\hline Home \\
\hline Society (parks and children's playgrounds) \\
\hline Role of home and school cooperation \\
\hline Physical support \\
\hline Role of school environment \\
\hline Peace stations \\
\hline Hats and badges \\
\hline Peace treaty \\
\hline Emotional support \\
\hline School authorities \\
\hline Families and close relatives \\
\hline Peers (school and relatives) \\
\hline Educational Empowerment \\
\hline Program \\
\hline Design and implementation \\
\hline Method of choosing mediators \\
\hline Teaching method \\
\hline Character of instructor \\
\hline Empirical learning \\
\hline Class instruction \\
\hline Development \\
\hline Teaching lower grades \\
\hline Teaching parents \\
\hline Teaching teachers \\
\hline Supporting and teaching same age peers \\
\hline Teaching middle-and high-school students \\
\hline Maintenance and improvement \\
\hline Teaching staff support \\
\hline Parents' support \\
\hline Providing program feedback to parents \\
\hline Cooperation between educational authorities and parents \\
\hline Supporting and encouraging students \\
\hline Harmony between educational authorities and parents \\
\hline Impact (individual and social) \\
\hline Boosting team spirit \\
\hline Increasing empathy \\
\hline Understanding interpersonal differences \\
\hline Improving interpersonal relationships \\
\hline Creating a safe and happy environment \\
\hline $\begin{array}{l}\text { Creating the tendency in lower grade students to cooperate in the } \\
\text { program }\end{array}$ \\
\hline Decreasing inter-individual differences \\
\hline Educational time management \\
\hline Supporting peers \\
\hline Trusting peers \\
\hline Fostering friendship \\
\hline Increasing self-confidence \\
\hline Encouraging obligation and a sense of responsibility \\
\hline Reinforcing learning \\
\hline Enhancing anger management \\
\hline Increasing awareness of peace and mediation \\
\hline
\end{tabular}

obvious. The impacts of the program can be summarized as: increased group morale and empathy, a better understanding of inter-personal differences, improved interpersonal communications, creating a safe and happy atmosphere, support of peers, trusting peers, making friends, increased self-esteem, feeling of dedication and responsibility, strengthened learning, improved anger control, increased awareness, and a better attitude towards peace and mediation.

"I was nervous at first, but then I told myself that other kids are doing this. I watched a few cases and that was how I gained my self-confidence. After that, I became good at mediating" (S 13).

"My son was very quiet. Ever since he has become a peace mediator he has become courageous, speaks out, and even calms me when I sometimes become angry at home" (P 11).

"There are much less fights and conflicts in the playground. Children try to solve their problems by talking. I remember a fight in which the boys said "no need to go to the station lets shake hands ourselves". It is very good that they have reached this level of communication" (E.A.1).

"Children in any age group are eager to participate in this project and it has been interesting for all of them" (E.A. 8).

A sample of the conceptual framework for the qualitative analysis of the interviews is demonstrated in Table 2 , and themes, sub-themes, and extracted codes from the interviews are pointed in Table 3.

\section{Discussion}

This study was conducted to establish a framework of factors on empowering primary school students in peer mediation. The results of the study were classified into two main categories of educational and social empowerment, two themes of program and advocacy, and seven subthemes. The "program" theme included four subthemes: design and implementation, development, maintenance and improvement, and social and individual impact. The "advocacy" theme included three subthemes: social, emotional and physical advocacy (Figure 1).

Concerning the educational empowerment of students, all the stakeholders mentioned the children's participatory and experiential learning, and believed that unofficial training was the key to the students' effective and deep learning. Tones are one of the opinions, according to which the learners' active involvement not only increases learning, but also empowers them. This type of learning supports training life and health skills and develops performance competence; the most effective methods of training in health are student-centered approaches (22). Studies conducted on peace education by Fountain and Bretherton confirmed this finding and considered experiential and participatory learning as a key method in acquiring and institutionalizing awareness, perspectives, skills and structural tendencies related to 


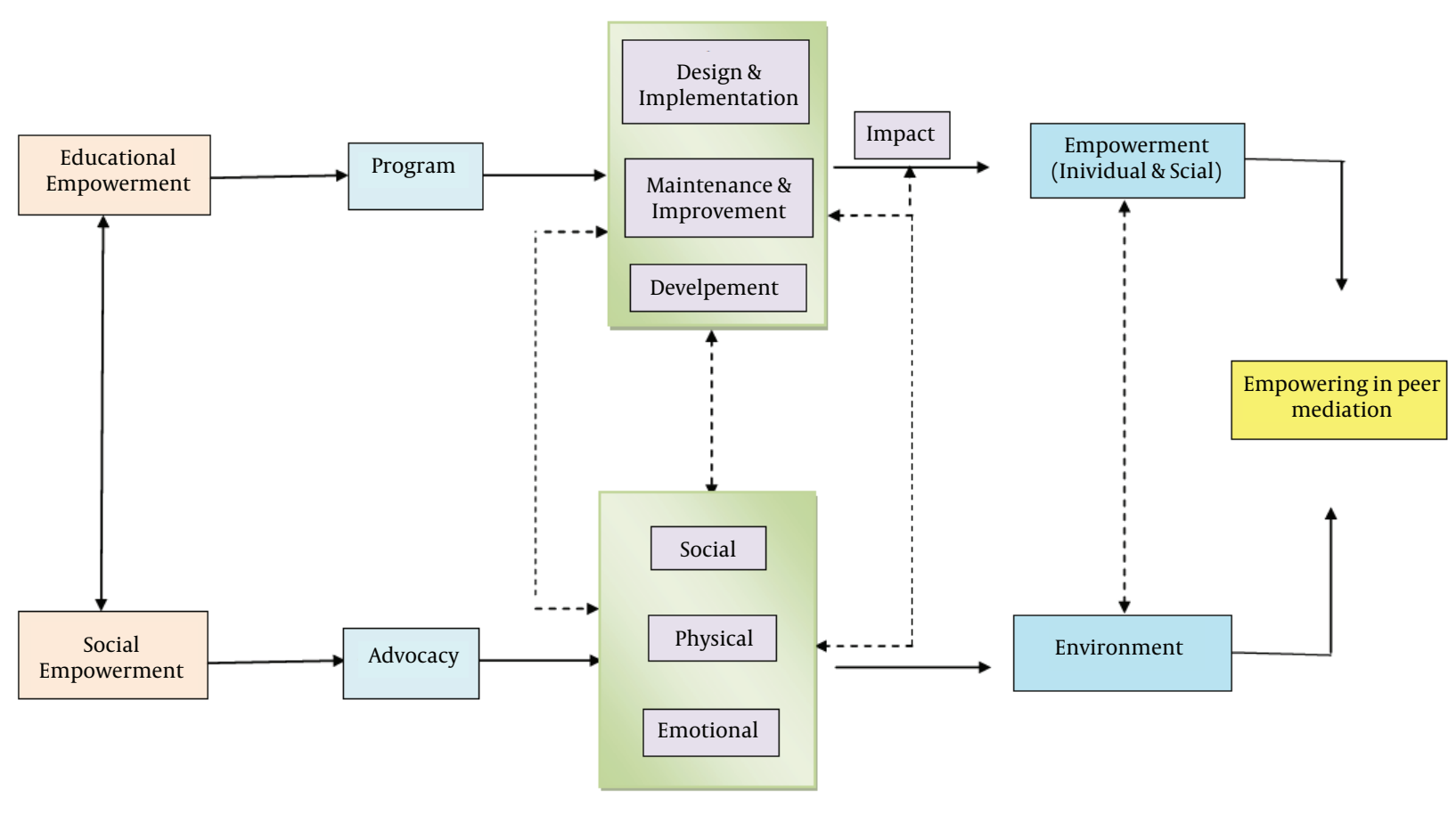

Figure 1. A Framework of Influential Factors on Empowering Primary School Students in Peer Mediation

peace $(23,24)$. Therefore, taking into account the effects of participatory teaching methods in raising knowledge, attitude, and empowering children in social skills, such unofficial and experiential methods should be applied in peace education and peer mediation programs. In addition, a supportive environment should be provided for students to encounter their natural problems. The stakeholders believed advocacy to be the fundamental factor in empowering students and addressed physical, social and emotional aspects of the support. For example, parents stated that receiving an appropriate feedback from the system and staying informed of the mediators' performance in school increases their participation in the program and subsequently their support. This feedback was not possible without the support of the management and subsequent cooperation of the education authorities. Hence, "advocacy" had a significant effect on maintaining and improving the "program" and they were not separated entities, but related to each other (Figure 1). They also addressed the significant role of environmental support, without which student empowerment would not be possible. According to them, although teaching the necessary skills to students was not ineffective, the role of environmental support in their participatory activities was the basic proviso of student empowerment in mediation. The abovementioned results complied with those of earlier studies. The statements made by Eng also supported these findings and addressed the positive role of social networks and social support on physical, spiritual, and social health. Strengthening social networks and modifying social support systems can reinforce the community ability in problem-solving (25). Systematic approaches toward health promotion have also focused on changing policies and environmental conditions and creating sustainable changes through participation and supportive environmental development $(26,27)$. Different studies have highlighted the role of the school physical and social environments and their positive and negative effects on children's behaviors and development (28-30). Eventually, creating positive and supportive environments has led to healthier lifestyles (31). Health promotion is concerned not only with direct actions and performances, strengthening life skills and individual capacities, but also with the social conditions and environments affecting health. In this context, health promotion has been focused on creating conditions that have had a better chance for individual and group efforts and their subsequent health outcomes (32). Therefore, using a participatory and experiential approach, and changing the school environments along with support and implementation of various policies (physical, social and emotional) can make peace education and the empowerment of schoolchildren in peer mediation possible.

\subsection{Limitations and Future Studies}

This study was the first peace education and conflict resolution research in Iran, only a few schools in Tehran (the sixth district) volunteered to implement this program, especially females' schools. The influential factors on empowering primary school students in peer media- 
tion must be stated and assessed from the stakeholders' point of view in females' schools. In addition, it should be performed in different SES levels and in different cultures in Iran.

\subsection{Implications}

School health plays a pivotal role in the assessment of current social needs through identifying factors in a school setting. A school social health can be promoted by the implementation of systematic and comprehensive programs, based on educational and social empowerment. However, all the nonteaching staff and education authorities in a school community must be dedicated to the program. With a supportive and participatory environment based on "peace and empowerment", schoolchildren will be encouraged toward supportive and safe behaviors. Educational empowerment and social empowerment are the two fundamental bases of peace education and peer mediation programs. Without question, the individual empowerment of a schoolchild does not lead to social empowerment and healthy behaviors. To achieve this goal, it is necessary to form the schoolchildren's behavior on social grounds, and the required space to learn; practicing and applying these skills must be provided. Educational empowerment attempts to promote individual skills and attitude by evaluating an individual's needs, and also through the design, programming and implementation of the program. Social empowerment is possible through support and a change in policies of the school system.

\section{Acknowledgements}

It was conducted with the support of the Center for Community Based Participatory Research. We would also like to extend our gratitude to Mr. Abdollah Habibi, the schoolmaster of Andisheh male primary school; the students, parents and education authorities, without whose support the task could not have been accomplished.

\section{Authors' Contributions}

Hamideh Jorbozeh developed the original idea and the protocol, abstracted and analyzed the data, wrote the manuscript. Mohammad H. Taghdisi contributed to the guidance of the protocol and monitoring the data analysis. Tahereh Dehdari contributed to the guidance of the protocol, monitoring the data analysis and revising the manuscript. Mahnaz Ashoorkhani contributed to revising the manuscript and data analysis.

\section{Funding/Support}

This study was supported in part by the Grant No. 90-0462-16277 from Tehran University of Medical Sciences.

\section{References}

1. Better schools through health: learning from practice. In: Buijs
G, Jociutė A, Paulus P, Simovska V editors. Case studies of practice presented during the third European Conference on Health Promoting Schools, held in Vilnius. 2009 Lithuania. Netherlands Institute for Health Promotion: pp. 15-7.

2. Güneri OY, Coban R. The effect of conflict resolution training on Turkish elementary school students: a quasi-experimental investigation. Int J Adv Couns. 2004;26(2):109-24.

3. Oliver Smith A. Involuntary resettlement, resistance and political empowerment. J Refug Stud. 1991;4(2):132-49.

4. Senghaas D. The Civilisation of Conflict: Constructive Pacifism as a Guiding Notion for Conflict Transformation. Transforming Ethnopolitical Conflict: Springer; 2004. pp. 25-39.

5. Turnuklu A, Kacmaz T, Sunbul D, Ergul H. Effects of Conflict Resolution and Peer Mediation Training in a Turkish High School. Aust J Guid Couns. 2010;20(1):69-80.

6. Johnson DW, Johnson RT. Implementing the" Teaching Students to be Peacemakers Program". Theory Pract. 2004;43(1):68-79.

7. Clayton CJ, Ballif Spanvill B, Hunsaker MD. Preventing violence and teaching peace: A review of promising and effective antiviolence, conflict-resolution, and peace programs for elementary school children. Appl Prev Psychol. 2002;10(1):1-35.

8. Thomas CO. Benefits and key components of peer mediation programs: University of Wisconsin-Stout; 2008.

9. Moon AM, Mullee MA, Rogers L, Thompson RL, Speller V, Roderick P. Helping schools to become health-promoting environmentsan evaluation of the Wessex Healthy Schools Award. Health Promot Int. 1999;14(2):111-22.

10. Wyn J, Cahill H, Holdsworth R, Rowling L, Carson S. MindMatters, a whole-school approach promoting mental health and wellbeing. Aust N Z J Psychiatry. 2000;34(4):594-601.

11. Bryan J, Henry L. Strengths-based partnerships: A school-familycommunity partnership approach to empowering students. Prof School Couns. 2008;12(2):149-56.

12. Eriksson M, Lindstrom B. A salutogenic interpretation of the Ottawa Charter. Health Promot Int. 2008;23(2):190-9.

13. Johnson DW, Johnson RT, Dudley B. Effects of peer mediation training on elementary school students. Mediation $Q$. 1992;10(1):89-99.

14. Turnuklu A, Kacmaz T, Turk F, Kalender A, Sevkin B, Zengin F. Helping students resolve their conflicts through conflict resolution and peer mediation training. Procedia Soc Behav Sci. 2009;1(1):639-47.

15. Jorbozeh H, Dehdari T, Hassanzadeh A, Taghdisi MH, Hosseini AF. The effectiveness of the Peer Mediation model on empowering primary school students in conflict resolution. Life Sci J. 2013;10(4):217-22.

16. Jorbozeh H. Peace education and empowering primary school students in peer mediation. Tehran Univ Med Sci. 2012.

17. Powell RA, Single HM. Focus groups. Int J Qual Health Care. 1996;8(5):499-504.

18. Dicicco-Bloom B, Crabtree BF. The qualitative research interview. Med Educ. 2006;40(4):314-21.

19. Polit DF, Beck CT. Essentials of nursing research: Appraising evidence for nursing practice: Lippincott Williams \& Wilkins; 2010.

20. Malterud K. Qualitative research: standards, challenges, and guidelines. Lancet. 2001;358(9280):483-8.

21. Fossey E, Harvey C, McDermott F, Davidson L. Understanding and evaluating qualitative research. Aust $N$ Z J Psychiatry. 2002;36(6):717-32.

22. Green J, tones K. Health Promotion Planning and Strategies. 2th ed: SAGE; 2010.

23. Peace education in UNICEF. New York; UNICEF. 1999.

24. Bretherton D, Weston J, Zbar V. Peace education in a post-conflict environment: the case of Sierra Leone. Prospects. 2003; 33(2):219-30.

25. Eng E, Parker E. Measuring community competence in the Mississippi Delta: the interface between program evaluation and empowerment. Health Educ Q. 1994;21(2):199-220.

26. Rowling L, Jeffreys V. Capturing complexity: integrating health and education research to inform health-promoting schools policy and practice. Health Educ Res. 2006;21(5):705-18.

27. Whitelaw S, Baxendale A, Bryce C, MacHardy L, Young I, Witney 


\section{Jorbozeh H et al.}

E. 'Settings' based health promotion: a review. Health Promot Int. 2001;16(4):339-53.

28. Kumar R, O'Malley PM, Johnston LD. Association between physical environment of secondary schools and student problem behavior: A national study, 2000-2003. Environ Behav. 2008;40(4):455-86.

29. Tanner CK. Effects of school design on student outcomes. JEduc Adm. 2009;47(3):381-99.

30. Limbos MA, Casteel C. Schools and neighborhoods: organiza- tional and environmental factors associated with crime in secondary schools. J Sch Health. 2008;78(10):539-44.

31. Archambault I, Janosz M, Morizot J, Pagani L. Adolescent behavioral, affective, and cognitive engagement in school: relationship to dropout. J Sch Health. 2009;79(9):408-15.

32. Lee A, Tsang C, Lee SH, To CY. A comprehensive "Healthy Schools Programme" to promote school health: the Hong Kong experience in joining the efforts of health and education sectors. J Epidemiol Community Health. 2003;57(3):174-7. 